\title{
EL SURGIMIENTO DEL RELATO FANTÁSTICO EN LA COSTA RICA DE LA PRIMERA MITAD DEL SIGLO XX
}

\author{
Ruth Cubillo Paniagua \\ Universidad de Costa Rica \\ rutycu@hotmail.com
}

Recibido: 29-04-2014

Aceptado: 18-07-2014

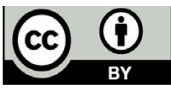

\section{REsumen}

El interés de este trabajo es indagar algunas de las razones por las cuales fue posible el surgimiento del relato fantástico y/o gótico -en la literatura costarricense de finales del siglo xIx e inicios del siglo xx- en un contexto socio-cultural que propiciaba y promovía la producción de literatura costumbrista y realista, más acorde con el naciente proyecto de estado-nación costarricense. Para ello se analizan diversas historias de la literatura costarricense, así como algunos textos históricos y una selección de cuentos fantásticos y/o góticos publicados por autores pertenecientes a la generación del Olimpo y a la generación del Repertorio Americano, bajo las cuales se agrupan los autores más representativos de este período de estudio.

PALABRAS ClAVE: Literatura fantástica, literatura gótica, literatura costarricense.

Abstract

This essay presents reasons for the rise of fantastic/gothic fiction in Costa Rica during a time (late nineteenth- and early twentieth-century) when "costumbrista" and realist fiction dominated because of the process of building a nation-state. I analyze several histories of Costa Rican national literature, some historical texts, and a selection of fantastic and gothic fiction published by writers of the Olimpo and Repertorio Americano generations.

Keywords: Fantastic fiction, gothic fiction, Costa Rican literature.

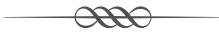




\section{INTRODUCCIÓN}

Al revisar las principales historias de la literatura costarricense (Abelardo Bonilla, 1957; Virginia Sandoval de Fonseca, 1978; Jorge Valdeperas, 1979; Flora Ovares y Margarita Rojas, 1995, y Álvaro Quesada, 2008) nos damos cuenta rápidamente de que lo fantástico como género literario no está demasiado presente en tales textos historiográficos, quizá porque nunca ha sido visto como un género predominante ni con una fuerte presencia en la literatura de este país, o quizá porque estos historiadores de la literatura no le han otorgado la atención que requiere dicho género. Lo cierto del caso es que si efectuamos una revisión más detallada del corpus de la literatura nacional, podemos afirmar que en Costa Rica se publicaron relatos fantásticos y/o góticos desde la última década del siglo xix y se han continuado publicando desde ese momento.

El interés de este trabajo es indagar algunas de las razones por las cuales fue posible el surgimiento del relato fantástico y/o gótico -en la literatura costarricense de finales del siglo xIX e inicios del siglo xx-en un contexto socio-cultural que propiciaba y promovía la producción de literatura costumbrista y realista, más acorde con el naciente proyecto de estado-nación costarricense. Para ello analizaré las citadas historias de la literatura costarricense, así como algunos textos históricos y una selección de cuentos fantásticos y/o góticos publicados por autores pertenecientes a la generación del Olimpo y a la generación del Repertorio Americano.

Nos planteamos ahora varias preguntas fundamentales para nuestros fines. ¿Existió en la literatura costarricense de las primeras cuatro décadas del siglo xx narrativa fantástica o más bien aquello que se produjo predominantemente fue narrativa fantástica con fuertes tintes góticos? ¿Cuáles son las diferencias fundamentales entre ambos géneros? ¿Es el gótico un subgénero de lo fantástico o más bien el gótico es un género madre del cual surge luego lo fantástico? ¿Qué condiciones socio-históricas permitieron que en las últimas décadas del siglo xIx y las primeras del siglo xx se produjera en Costa Rica este tipo de literatura?

Mi tesis es que en Costa Rica, durante el citado período, podemos hablar de la existencia de una veta de literatura fantástica, pero fuertemente marcada por ciertos elementos de la literatura gótica, aunque siempre como un tipo de literatura minoritaria respecto de la clara y contundente mayoría representada por la literatura realista-naturalista-costumbrista. 


\section{LO FANTÁSTICO EN LA HISTORIOGRAFÍA LITERARIA COSTARRICENSE}

La primera parada obligatoria es la Historia de la literatura costarricense (1957) de Abelardo Bonilla. En este texto ni siquiera se contempla lo fantástico como una posibilidad de la literatura costarricense, pues para Bonilla el aislamiento espiritual y material de este país, así como las características del hombre costarricense y la baja densidad de la población, permiten afirmar que «la característica más definida de la literatura costarricense, desde el período colonial, es el predominio del pensamiento y la aventura conceptual sobre la poética (...) Estas circunstancias han contribuido a darle preferencia en nuestra producción literaria a la Historia y al Derecho sobre las formas de creación poética. (...) la modalidad civil y democrática de la nación y el predominio de las dos ramas literarias citadas, influyeron en la tonalidad general de la literatura costarricense: claridad, lógica, laicismo, equilibrio y mediocridad (...)» (Bonilla, 1957: 33-34)

Por su parte, ni Virginia Sandoval de Fonseca, en su Resumen de la literatura costarricense (1978), ni Jorge Valdeperas Acosta, en su obra Para una nueva interpretación de la literatura costarricense (1978), mencionan que existiera literatura fantástica en Costa Rica en la primera mitad del siglo xx. Ambos autores dan por sentado que nuestra literatura de aquellos años fue únicamente realista, costumbrista o modernista.

Flora Ovares y Margarita Rojas, en 100 años de literatura costarricense (1995), tampoco señalan la existencia de literatura fantástica en Costa Rica durante el período aquí estudiado, aunque cuando analizan algunos textos, por ejemplo «Espiritismo» (1918) de Carlos Gagini, le abren una ventana a esta posibilidad: «El personaje aparece arrancado de una existencia anónima, sin sobresaltos, por un acontecimiento para él extraordinario y ajeno a su vida cotidiana. Se trata de la pasión amorosa que, a veces, como en "Espiritismo" (...) está rodeada de circunstancias misteriosas y fantásticas» (Rojas y Ovares, 1995: 46). Sin embargo, estas autoras, al igual que Álvaro Quesada Soto en su Breve historia de la literatura costarricense (2008), prefieren ubicar este tipo de textos dentro del modernismo exotista y academicista que durante algunos años corrió paralelo al realismo costumbrista, con lo cual evitan plantear la existencia de narrativa fantástica en el país.

\section{LiterATURA FANTÁSTICA/LiterATURA GóticA}

Para entender las diferencias más importantes entre literatura gótica y literatura fantástica, me basaré en los trabajos de David Roas (2001, 2003 y 
2011) y Miriam López Santos (2010). La primera diferencia consiste en afirmar que en los relatos góticos no se genera una identificación del lector con las coordenadas espacio-temporales que se manejan en el texto, es decir, lo gótico no aborda lo cotidiano para el lector, pues en este género impera

[...] siempre una lejanía temporal con respecto a los hechos narrados, que [...] entra en conflicto con aquella necesaria «percepción de lo real» exigida por el relato fantástico. Las historias góticas se desarrollaban siempre en un tiempo pasado, remoto y oscuro [...] En la literatura fantástica [...] por contra, hallamos tan solo mínimas alteraciones en la realidad cotidiana del texto, que se presenta como perfectamente identificable para los lectores, que experimentan, por ello, la misma sensación de inquietud que los personajes, al reconocerse en los lugares y situaciones que se muestran. (López Santos, 2010)

La segunda diferencia tiene que ver con la noción de verosimilitud que se maneja en los relatos góticos y en los fantásticos. En los primeros,

[...] la verosimilitud contextual se quiebra, gracias no solo el distanciamiento de las coordenadas espaciotemporales del texto con respecto a las del lector -que produce un desfase entre el (tiempo del) mundo (extradiegético) aludido por el narrador y el de su posterior lectura-, sino también por la falta de una localización espacial demasiado precisa. La referencia a lugares concretos, acontecimientos históricos, nombres reales o descripciones minuciosas de personajes o ambientes resulta demasiado tenue como para poder mantener esta verosimilitud, cuestionando, de esta manera, el proceder de la novela gótica en función de la estructura del relato fantástico. (López Santos, 2010)

Mientras que en el relato fantástico, es indispensable mantener la verosimilitud, pues «al precisar de un mundo real, necesitaba afirmar su propia existencia, su propia verdad (...) manifestar a cada pasaje esa verosimilitud, ofreciendo al destinatario los elementos para que este lo aceptara como verificable» (López Santos, 2010).

La tercera diferencia consiste en plantear que el objetivo fundamental del relato gótico es producir en el lector miedo o terror, mientras que el relato fantástico aspira a producirle angustia, inquietud, desasosiego. Al respecto, López Santos señala que el miedo es el juego que «más allá de la transgresión, el autor establece con protagonista y lector a base de hurgar en los terrores que recorren nuestras conciencias y nuestras pesadillas diarias y que estos acceden a tomar partida» (López Santos, 2010). Por ello en los relatos góticos se insiste en «la maldad humana, los deseos ocultos, las perversiones sexua- 
les, el contacto con el más allá» (López Santos, 2010), todo aquello reprimido por la excesiva racionalidad promulgada y difundida por la Ilustración.

La cuarta diferencia tiene que ver con la explicación o no explicación de los hechos que se presentan en el relato, pues mientras que en el relato fantástico se procura dejar la duda en el lector, en el relato gótico se ofrece en muchas ocasiones una explicación racional de lo acontecido, con lo cual se disipa la duda inicial. En este sentido, López Santos señala: «Todos los hechos aparentemente sobrenaturales son pasados por el filtro de la razón al recibir una explicación exhaustiva, racional y realista, pero inverosímil y contraria a la causalidad general del texto, por lo que nada queda suelto a la imaginación del lector, efecto fundamental (...) que deben experimentar las narraciones fantásticas (López Santos, 2009). Y lo que fuera creado con la pretensión de ser «inexplicable» ("no se puede explicar") «acaba por convertirse en «inexplicado» ("puede explicarse"), procedimiento que aproxima el relato gótico más a la novela policiaca clásica que a la narración fantástica tradicional» (López Santos, 2010).

Después de realizar un recorrido por la literatura europea de los siglos xVIII y xIx, López Santos defiende

[...] la teoría de la ficción gótica como género origen, pero independiente de lo fantástico [...], partiendo de lo maravilloso y legendario y apoyada en la pugna entre la preeminencia del irracionalismo o la persistencia en la razón, se configuró como género madre susceptible de escindirse en renovados géneros literarios con estructuras ya perfectamente fijadas y delimitadas, gracias a la riqueza de su problemática y, al mismo tiempo (y derivado de esta), a la escasa consistencia de sus mecanismos. (López Santos, 2010)

Ahora bien, considero que para el caso de Costa Rica podemos aplicar parcialmente esta teoría de la ficción gótica postulada por López Santos. Trataré de explicar por qué. En este país, en las últimas décadas del siglo xIx y las primeras del siglo xx se afianzó la ideología liberal, en muchos sentidos heredera de los postulados de la Ilustración europea, ideología que se proponía alfabetizar, instruir, higienizar y racionalizar al pueblo costarricense, que hasta ese momento (1850-60) por lo visto había sido analfabeto, sucio y supersticioso.

Así, en el cambio del siglo xix al xx, San José era una ciudad que caminaba hacia la modernización y el progreso, de acuerdo con las políticas públicas de la oligarquía liberal, que desde la segunda mitad del siglo xix gobernaba el país. Sin embargo, este tránsito no fue gratuito y generó consecuencias que para 
algunos sectores de la sociedad no eran deseadas. En novelas como El primo de Jenaro Cardona, Las hijas del campo, de J. García Monge, o El árbol enfermo, de Carlos Gagini, se pone en evidencia el surgimiento de este debate entre los valores tradicionales de la sociedad costarricense y los nuevos valores generados por el aire de progreso que, además, resultaba imposible detener. Como muestras materiales de esta modernización capitalina tenemos que en 1900, en la administración de Rafael Yglesias, se inauguró el tranvía en San José y se trajo a la ciudad el primer automóvil, cuyo propietario fue Enrique Carranza.

Como mencionamos, una de las grandes preocupaciones de los políticos liberales costarricenses fue higienizar el país (en especial se preocuparon por el valle central ${ }^{1}$ ), con el fin de crear las condiciones necesarias para implementar sus planes progresistas: una ciudad enferma y sucia era incapaz de progresar.

Sin embargo, tal y como afirman Molina y Palmer,

[...] el afán civilizador de los liberales tuvo un resultado paradójico: en 1930, una mayoría de los 500.000 costarricenses sabía leer y escribir, aceptaba los valores y los símbolos del nacionalismo y participaba en las campañas electorales. El primer tercio del siglo $\mathrm{xx}$, sin embargo, se caracterizó por el desgaste de la ideología del progreso (...) La generación que surgió a partir de 1900, en la que destacó el novelista Joaquín García Monge (...) avizoró debajo del grano de oro una agudizada "cuestión social": burgueses corruptos y egoístas, y trabajadores pobres a los que urgía redimir mediante una educación apropiada. (Molina y Palmer, 1997: 63 y 65).

Según la lógica liberal y a partir de la ideología del progreso, las fuerzas del mercado por sí mismas regularían la economía basada en las exportaciones agrícolas y en la creciente industria, ${ }^{2}$ y esto conduciría el país al pro-

1 Para profundizar en el tema de los orígenes de la salud pública y la higienización en Costa Rica, cf. Malavassi (2003).

2 En este sentido, el sociólogo Mario Ramírez señala: «Con el desarrollo capitalista el mercado interno se cumplía en un doble sentido: por un lado, artículos y actividades del sector informal de la economía se convierten en mercancías; por el otro, capitales ociosos o de baja rentabilidad en los mercados tradicionales buscan nuevos ámbitos donde valorizarse. Así, productores de industrias de autoconsumo se ven impulsados a la pequeña producción mercantil como medio para organizar su mano de obra. También los artesanos se arriesgan a erigir modestos talleres, algunas veces organizados en uniones o agrupados en sociedades mercantiles. La gran masa de ellos apenas reproduce su propia existencia como pequeño-burgueses hasta la nueva generación, en un proceso de lento empobrecimiento que confunde la vejez con la inutilidad y la decadencia. Algunos sectores tienen el "privilegio" de proletarizarse solo cuando lo permiten las coyunturas del mercado y la producción, o su propio estilo de vida, en la medida que la clase proletaria debe interiorizar una disciplina laboral y política. La férrea disciplina laboral permite a unos pocos aburguesarse (...)» (Ramírez, 1983: 102). 
greso, la civilización y la prosperidad para todos, pero ante las consecuencias económicas de la Primera Guerra Mundial iniciada en 1914 y de la gran depresión de 1929, resultó más que evidente que este proyecto económico liberal no tenía las respuestas adecuadas y necesarias para afrontar la nueva situación económica; por ello, cuando cayó el modelo agro-exportador debido a la disminución de los precios del café y el banano en el mercado internacional, resultó necesario plantear y aplicar nuevas políticas públicas y entonces las élites gobernantes optaron por la intervención estatal para regular la economía y mantenerla lo más sana posible.

En este contexto, se conforma en nuestro país un nuevo núcleo generacional (los «intelectuales radicales») cuyos orígenes podemos ubicar durante las primeras grandes crisis de régimen liberal y del capitalismo agrario dependiente. (Quesada Soto: 1986, 1988)

Estas crisis ponen en evidencia los grandes problemas, tanto de índole política como económica, del llamado estado nacional, pero también hacen que estos nuevos intelectuales cuestionen los límites de la democracia y del patriotismo (asociado generalmente a la defensa de la soberanía nacional) que pregonaba a los cuatro vientos la oligarquía liberal costarricense. Esta oligarquía comienza a ser cuestionada por la nueva intelectualidad, que consideraba que muchas veces los oligarcas anteponían sus intereses personales (comerciales y financieros) a los intereses de la nación, es decir, pensaban que el pueblo, la clase trabajadora, les importaba poco.

Las fracturas generadas a lo interno de la estructura oligárquica, ya se evidenciaban hacia 1860, año en que fueron fusilados los generales Juan Rafael Mora y José María Cañas por orden de sus adversarios políticos. A pesar de estas divisiones, la unidad que simbolizaba esta élite dominante era suficiente para que otros grupos sociales subalternos surgieran en oposición a sus propuestas económicas, políticas y culturales. Podríamos decir que en estas primeras dos décadas del siglo xx, la sociedad costarricense estaba claramente fragmentada en razón de la división de clases, es decir, había ricos y pobres.

Ahora bien, lo cierto es que tanto dentro de la llamada generación del Olimpo como dentro de la llamada generación del Repertorio Americano encontramos intelectuales que podríamos considerar defensores del racionalismo ilustrado, pero son precisamente muchos de esos intelectuales los que llegan a comprender que no todo lo que llamamos realidad puede ser explicado racionalmente, es decir, que existe un punto de fractura o de quiebre dentro de la lógica de la razón. Para explicar esto, muchos de ellos recurren al 
estudio de lo terrorífico, lo misterioso, lo oculto, lo oscuro, lo inexplicable; por eso no es extraño que muchos de estos intelectuales liberales y radicales se adentraran en el esoterismo, la teosofía y el ocultismo, tal y como lo podemos constatar estudiando sus referencias biográficas.

En este sentido, David Roas señala que, «si bien el desarrollo del racionalismo [se refiere al racionalismo surgido y consolidado en el siglo XVIII en Europa] eliminó la creencia en lo sobrenatural, ello no supuso la desaparición de la emoción que producía como encarnación estética el miedo a la muerte y a lo desconocido (un sentido de lo sobrenatural ajeno al que exploraba, por ejemplo, el cuento de hadas» (Roas, 2011: 17).

Es muy importante entender que el hecho de que muchos de estos escritores costarricenses eligieran la veta gótica para «desviarse» del camino del racionalismo realista tiene que ver con su certeza de que en el horizonte de expectativas de los lectores costarricenses de este período (y en el suyo propio) permanecía todo ese mundo monstruoso y terrorífico; en palabras de López Santos:

Si bien (...) las supersticiones y los milagros habían sido arrinconados por los preceptos de la razón, lo sobrenatural pertenecía aún al horizonte de expectativas del lector; fantasmas, monstruos y demás fenómenos y seres infestos se conservaban latentes en la memoria colectiva como restos de un pasado lejano y oscuro. Los narradores góticos, en el deseo de experimentación con los terrores humanos y ante la falta de referencia directa en su mundo diario, vieron en aquel pasado un marco perfecto para el desarrollo de sus tramas. (López Santos, 2010)

Así pues, entre 1880 y 1940 se publicaron en Costa Rica diversos relatos cuya preocupación fundamental consistía en detenerse en lo misterioso, lo extraño, lo oculto e incluso lo terrorífico. La mayoría de estos relatos mezclan o conjugan características de lo que hoy claramente distinguimos como fantástico y como gótico, pero que en aquellos años no se distinguía con claridad. Lo cierto es que estos autores costarricenses quisieron abrir un espacio dentro de su producción literaria a estas historias extrañas, sorprendentes y misteriosas.

En este sentido, resulta muy pertinente la afirmación de Roas: «La emoción de lo sobrenatural, expulsada de la vida, encontró refugio en la literatura. Ese nuevo interés estético coincide (y no por casualidad) con el desarrollo del gusto por lo horrendo y lo terrible, una nueva sensibilidad -lo sublimeque tomaba el horror como fuente de deleite y de belleza» (Roas, 2011: 17). 
Así pues, el cuento «La poza de la Sirena» (1880) de Manuel Argüello Mora, quizá sea uno de los primeros que se centra en una temática misteriosa. En este relato se mezclan la leyenda con lo fantástico y lo moralizante; el personaje principal, Arturo, es un hombre joven, de buena posición económica, bien casado, ambicioso en exceso, e insatisfecho con lo que la vida le había dado, que según el narrador, era mucho. La irrupción de la sirena en la vida cotidiana de Arturo constituye el único elemento fantástico del cuento (se recurre a la leyenda para explicar su origen); esta es presentada como un ser misterioso, poderoso, y capaz de ver y cambiar el futuro.

Cabe destacar que, para darle verosimilitud al texto, el encuentro con la sirena es narrado en primera persona por Arturo y no por el narrador omnisciente que se encarga de relatar el resto de la historia. Ahora bien, hacia el final del cuento ese narrador omnisciente se ocupa de explicarnos que todo lo que hemos leído hasta ese momento no es más que el producto de una ensoñación experimentada por Arturo como fruto de una droga, «el hastchiz», recetada por el Dr. Weber para mejorar el ánimo de su paciente. Esta explicación racional le resta su carácter fantástico al cuento, pues, saca al lector de la indispensable duda; en el último párrafo del cuento, más bien se brinda la moraleja: «Cuidado, pues, lector de mi alma, con las pastillas de hastchiz y procura sacar de esta novelita, la moralidad que en ella pudiera seros útil» (Argüello Mora, 1880, en Chaves, 2012: 31).

En «La perla negra», publicado por Ricardo Fernández Guardia en 1894 dentro de su colección Hojarasca, se nos habla de un objeto maldito, el mismo que da título al cuento. Esta perla produce la ruina o la muerte de todo aquel que la posee y por eso Villers, el personaje de ascendencia europea que le cuenta la historia de la perla a nuestro narrador, desea que esta sea adquirida por un «yanqui», pues él los detesta. Este objeto maldito no produce situaciones propiamente fantásticas, solo es generadora de catástrofes, con lo cual habría que valorar con detenimiento si «La perla negra» es en efecto un relato fantástico o se acerca más bien a la leyenda.

Por otra parte, en los cuentos «Espiritismo» (1918) de Carlos Gagini, «La medalla» (1920) de Ricardo Fernández Guardia y «Doble existencia» de Roberto Brenes Mesén encontramos un tema recurrente en la literatura gótica: la aparición de los muertos a los vivos. En estos tres relatos se trata de mujeres que después de muertas se les aparecen a los hombres amados, a quienes -por diversas circunstancias del destino- nunca pudieron entregarse carnalmente. Dos de los protagonistas, Raúl y Raimundo («Espiritismo» y «Doble existencia», respectivamente) mueren después de este encuentro con las amadas 
muertas, mientras que Fernando («La medalla») cae en la locura, la melancolía y la depresión; el cuento finaliza con las siguientes palabras de Fernando, dirigidas a nuestro narrador testigo: «Entre una muerta y yo existe un lazo misterioso e indisoluble, del que esa medalla desprendida de la cadena de mi reloj y encontrada por usted es el inexplicable y pavoroso testimonio.» (Fernández Guardia, 1920, en Chaves: 2012: 90). En ninguno de los tres casos se brinda una explicación lógica ante lo ocurrido, sino que se deja abierta la posibilidad para que el lector juzgue por sí mismo y saque sus propias conclusiones.

Ya en 1929, Jenaro Cardona publica un cuento titulado «La caja del doctor», como parte de su colección de relatos Del calor hogareño; aquí se acentúan los rasgos góticos presentes en los tres cuentos arriba mencionados, pues encontramos a un hombre extranjero, suizo para más señas, el doctor Milianikoff, quien por diferentes vueltas del destino se encontraba laborando en el Museo Nacional de Costa Rica, y a quien le ocurre un «extraño caso» (en clara alusión a la novela de R. L. Stevenson) que nos van a relatar. Este doctor era un alcohólico que lograba mantenerse abstemio por ciclos de siete años, al cabo de los cuales volvía a caer en el vicio irremediablemente; en una de estas recaídas, y mientras trabajaba en La Sorbona de París, el doctor mató a su esposa y metió el cadáver en una caja de la cual no se separaba nunca. Pues bien, ya instalado en San José, llegó el día en que se cumplían sus siete años de abstinencia: el 25 de noviembre. El doctor se encontraba en su laboratorio del Museo Nacional y se tomó el alcohol de los frascos que contenían reptiles y batracios, con lo cual no solo rompió su largo período de abstinencia, sino también la promesa que le había hecho a su esposa moribunda: no beber alcohol nunca más para así alejar el espíritu del mal que lo poseía cuando bebía.

La ruptura de esta promesa genera la ira del esqueleto de la esposa encerrado en la famosa y misteriosa caja, quien logra liberarse de su prisión y mata al doctor golpeándolo en la cabeza con una pesada maza de jade. Se trata entonces de un esqueleto asesino que castiga al mentiroso doctor; es importante señalar que el narrador omnisciente no nos brinda ninguna explicación racional de este macabro hecho, sino que más bien cierra el relato describiendo la escena del crimen, tal y como la encontró el conserje del museo al día siguiente, es decir, se trata de un narrador que procura ser objetivo e imparcial. En palabras de Cardona:

La cabeza del doctor presentaba una profunda herida en el parietal derecho, por la cual podía verse, entre coágulos sanguinolentos, una porción de la masa encefálica. La caja de ébano, que había contenido por tanto tiempo el esqueleto de marfilina blancura, estaba abierta a lado de unos pedazos de cristal de dos 
frascos (...) El esqueleto mantenía entre los huesos de la mano derecha, una maza de jade, primorosamente labrada, simulando una calavera, y manchada de sangre. (Cardona, 1929, en Chaves, 2012: 45)

Una descripción bastante gótica la descripción. «La marca azul» de Eduardo Calsamiglia es un cuento que presenta muchas características de la literatura gótica, pues se desarrolla en un lugar lejano a la realidad del lector costarricense de las primeras décadas del siglo xx, describe un hecho macabro y ofrece una explicación lógica de lo sucedido acorde con la verosimilitud intradiegética. Conviene señalar que estructuralmente este cuento resulta bastante novedoso para su época, pues Calsamiglia recurre al recurso del hallazgo de un manuscrito fragmentado e incompleto, que el narrador reconstruye de la mejor manera posible para nosotros, sus lectores. Gracias a este recurso, se nos presenta una historia fragmentada, con grandes saltos temporales e interrogantes sin responder.

La historia se desarrolla en el sombrío y lejano castillo de Tarento, España (como buen relato gótico) y nos habla del conde Diego de Tarento, quien amaba profundamente a su joven y bella esposa rusa, Aida, pero dudaba de su fidelidad. El conde visita a un astrólogo (especie de brujo) para que este le ayude a salir de dudas y le ofrece un brebaje que el conde debe poner en la bebida de su mujer. El efecto del brebaje consistía en dejar una marca azul en el rostro de cualquier hombre que besara Aida que no fuera su marido. Sin embargo, Nicolás Hartoff, un hombre despechado al que Aida había despreciado para casarse con el conde, escucha desde un escondite las instrucciones del astrólogo y le pone una trampa a Diego y Aida. Como resultado de esto, Diego mata a su inocente mujer y realiza con su cuerpo un acto absolutamente macabro: «Al otro día todo era duelo en el palacio de Tarento: tristes cruzaban los criados por las espaciosas góticas galerías. El cadáver de la joven fue quemado y sólo se conservó la cabeza por voluntad del conde con esta inscripción mortuoria: 'Para escarmiento de infieles'. Aquel fúnebre despojo fue sepultado en un enhiesto torreón cercano al Castillo» (Calsamiglia, 2008, en Chaves, 2012: 154).

El último cuento que aquí analizaremos se titula «El retrato hechizado» y fue publicado en la década de 1950 por Gonzalo Chacón Trejos como parte de sus Tradiciones costarricenses. Este cuento también presenta muchos rasgos propios de un relato gótico; desde las primeras líneas, el narrador señala que el cuento dará a aquellos que creen «en la magia, la hechicería y la brujería, motivo para afianzar su fe en las potencias sobrenaturales que ope- 
ran en el arcano de las fuerzas ocultas» (Chacón Trejos, 1956, en Chaves, 2012: 181). Esta introducción sin duda nos ubica más en el terreno de lo gótico que de lo fantástico, pues nos remite de inmediato al mundo del ocultismo y el espiritismo; en palabras de Chacón Trejos, nos lleva al mundo de los «creyentes apasionados en las manifestaciones, según ellos casi tangibles, de la vida más allá de la muerte» (Chacón Trejos, 1956, en Chaves, 2012: 181)

El hecho insólito y sorprendente que se narra en este cuento es el estallido de un espejo que se encontraba en casa de la familia Romero, en San José, Costa Rica. Las causas de tal estallido no quedan claras, pero lo que interesa relatar es que debajo del vidrio del espejo se hallaba un retrato del Dr. Castro Madriz. ${ }^{3}$ La explicación que nos brinda el narrador ante este extraño suceso es que el Dr. Castro Madriz era un hombre inteligente, bien parecido, con un gran don de gentes, todo lo cual generó gran envidia hacia él entre sus contemporáneos.

Esta fuerza negativa de la envidia ocasionó el hechizo del espejo de las Romero, pero ese hechizo se rompió el día en que un grupo de admiradores del Dr. Castro Madriz acordó brindarle un homenaje nacional al prócer:

El hechizo, el embrujo del retrato del doctor Castro ¿fue hecho por un enemigo mortal? ¿Lo hizo una mujer enamorada? Eso no se sabrá nunca. El hecho cierto y sorprendente es que al culminar la devoción hacia aquel hombre eminente, en la fiebre entusiasta por honrar y enaltecer su memoria, el embrujo, el hechizo, se desvaneció, quedó deshecho. ¿Hizo estallar al espejo una fuerza oculta y mágica? El retrato apareció, con triunfal esplendor, sugiriendo el hechizo y su inescrutable misterio. (Chacón Trejos, 1956, en Chaves, 2012: 186)

Como vemos, la explicación brindada no resulta muy racional, sino que más bien abre la puerta a otras posibilidades ubicadas más bien en el ámbito de lo sobrenatural.

\section{Conclusiones}

Como hemos podido comprobar al analizar estos cuentos, en la mayoría de ellos se presenta un elemento extraño o sobrenatural, pero que no necesariamente funciona como elemento generador de lo fantástico. Según apunta David Roas, una condición indispensable para señalar el carácter fan-

3 El doctor José María Castro Madriz fue Presidente de Costa Rica de 1847 a 1849 y de 1866 a 1868. La historiografía lo reconoce como el fundador de la primera República. Fue un liberal y creía firmemente en las bondades de la Ilustración y la racionalidad. 
tástico de un texto es la intromisión de lo sobrenatural, si bien aclara el autor que no todos los textos en los que sucedan hechos sobrenaturales -literatura medieval, literatura gótica, libros de caballerías o ciencia ficción- son fantásticos.

El contexto socio-cultural de las últimas dos décadas del siglo xIX y las primeras tres o cuatro décadas del siglo xx, posibilitó la publicación de una literatura marcadamente realista, costumbrista o incluso modernista, pero al mismo tiempo de una literatura, eso sí mucho menos numerosa que la anterior, a medio camino entre lo gótico y lo fantástico. Tuvimos que esperar hasta la década de 1960 para encontrar textos marcadamente fantásticos, como los publicados por Alfredo Cardona Peña, Cuentos de magia, de misterio y de horror (México, 1966) o La fábula contada (San José, 1972), los cuales han sido poco estudiados por la crítica.

\section{BIBLIOGRAFÍA}

Arán, Pampa (2001): Apuntes sobre géneros literarios, Epoké, Córdoba.

Baillois, Roger (1965): Au coeur du fantastique, Gallimard, París. (1970): Imágenes, imágenes..., Sudamérica, Buenos Aires.

BARrenecheA, Ana María (1978): Ensayo de una tipología de la literatura fantástica, Monte Ávila, Caracas.

Bonilla, Abelardo (1957): Historia de la literatura costarricense, Editorial Costa Rica, San José.

BozzetTo, Roger (2002): «El sentimiento de lo fantástico y sus efectos» en Quimera, (218-219), (julio-agosto de 2002), (pp. 35-40).

CABRE, Jean (1992): Le miroir de sorcière. Essai sur la littérature fantastique, José Corti, París.

Calvo DíAz, Karen (2013): La literatura gótica en Costa Rica: el discurso de lo subversivo a partir de la narrativa breve de José Ricardo Chaves. Tesis de Maestría en Literatura, Universidad de Costa Rica.

CAMpra, Rosalba (2000): Territori della finzione. Il fantástico en letteratua, Carocci, Roma. (2001): «Lo fantástico: una isotopía de la transgresión» en ROAs, David (Comp.) Teorías de lo fantástico, Arco libros, Madrid, pp. 151-191.

Chaves, José Ricardo (2012): Voces de sirena. Antología de literatura fantástica de Costa Rica. Primera mitad del siglo XX, URUK editores, San José.

Cllis, Markman (2000): The History of Gothic Fiction, Edinburgh University Press, Edimburgo.

Ferreras, Daniel (1995): Lo fantástico en la literatura y el cine: De Edgar A. Poe a Freddy Krueger. Ediciones Vosa, Madrid.

García Berrio, Antonio y Huerta Calvo, Javier (1992): Los géneros literarios: sistema e historia, Cátedra, Madrid. 
García SÁnchez, Francisco (1998): «Orígenes de lo fantástico en la literatura hispánica», El relato fantástico. Historia y sistema, Biblioteca Filología, Colegio de España, Salamanca.

JACKSON, Rosemary (1986): Fantasy: Literatura y subversión, Editorial Catálogos, Buenos Aires.

López Santos, Miriam (2010): «El género gótico. ¿Génesis de la literatura fantástica?». Disponible en http://www.cervantesvirtual.com/obra-visor/el-genero-gotico-genesis-de-la-literatura-fantastica/html/458dbc94-a0f8-11e1-b1fb-00163ebf5e63_6.html [15 de enero de 2014]

Malavassi, Ana Paulina (2003): Entre la marginalidad social y los orígenes de la salud pública: leprosos, curanderos y facultativos en el Valle Central (1784-1845), EUCR, San José.

Molina, Iván y Palmer, Steven (1997): Historia de Costa Rica, Eucr, San José.

Morillas Ventura, Enriqueta (1991): El relato fantástico en España e Hispanoamérica, Sociedad Estatal Quinto Centenario, Michigan.

Nikolajeva, María (1998): The Magic Code. The Use of Magical Patterns in Fantasy for Children, Almqvist \& Wiksell International, Estocolmo.

Olea Franco, Rafael (2004): En el reino fantástico de los aparecidos: Roa Bárcena, Fuentes y Pacheco, El Colegio de México, pp. 23-73.

QuesAdA, Álvaro (1986): La formación de la narrativa nacional costarricense (1890-1910), EUCR, San José.

(1988): La voz desgarrada: la Crisis del discurso oligárquico y la narrativa costarricense (1917-1919), EUCR, San José.

(2008): Breve historia de la literatura costarricense, Editorial Costa Rica, San José.

RAmírez BozA, Mario (1983): El desarrollo de las clases sociales y la industria en Costa Rica (1880-1930), Tesis de Licenciatura en Sociología, Universidad de Costa Rica.

RoAs, David (2001): «La amenaza de lo fantástico» en RoAs, David (Comp.), Teorías de lo fantástico, Arco libros, Madrid, pp. 7-44.

(2002): «Lo fantástico: literatura y subversión» (dossier monográfico), en Quimera, 218-219 (Julio-agosto de 2002), pp. 35-40.

(2003): «El género fantástico y el miedo» en Quimera, 218-219 (Julio-agosto de 2002), pp.41-45.

(2004): «Contexto sociocultural y efecto fantástico: un binomio inseparable» en Odiseas de lo fantástico, CILF, México.

(2006): De la maravilla al horror. Los inicios de lo fantástico en la cultura española (17501860), Mirabel Editorial.

(2011): La sombra del cuervo. Edgar Allan Poe y la literatura fantástica española del siglo XIX, Devenir, Madrid.

(2001): Teorías de lo fantástico. Arco/libros, Madrid.

(2011): Tras los límites de lo real. Una definición de lo fantástico, Páginas de Espuma, Madrid.

Rodríguez Pequeño, Francisco (1995): Ficción y géneros literarios, Ediciones de la Universidad Autónoma de Madrid, Madrid. 
RoJAs, Margarita y Ovares, Flora (1995): 100 años de literatura costarricense, Editorial Farben Norma, San José.

SÁnchez Escalonilla, Antonio (2009): Fantasía de aventuras: claves creativas en novela y cine, Editorial Ariel, Barcelona.

Sandoval, Virginia (1978): Resumen de la literatura costarricense, Editorial Costa Rica, San José.

SEgre, César (1985): Principios de análisis del texto literario, Crítica, Barcelona.

Todorov, Tzvetan (1982): Introducción a la literatura fantástica, Ediciones Buenos Aires, Barcelona.

VAldePERAs, Jorge (1979): Para una nueva interpretación de la literatura costarricense. Editorial Costa Rica, San José.

VAx, Louis (1973): Arte y literatura fantásticas, Eudeba, Buenos Aires.

(1975): La séduction et l'étrange. Étude sur la littérature fantastique, PUF, París. 